\title{
XXI. Memoranda relative to Clovelly, Nortb Devon.
}

By the Rev. J. J. Conybeare, Member of the Geological Society.

In a Letter addressed to G. B. Greenovgh, Esq. V. Pr. G.S.

My Dear Sir,

WF either the enclosed memoranda relative to the neighbourhood of Clovelly, or the drawings which accompany them possess any interest, they can derive it only from the consideration that the geological features of that remarkable spot do not hitherto appear to have attracted the attention of any person engaged in those studies which it is the object of our Society to promote. The former, though, I trust accurate, are, I fear, extremely scanty. The latter I can only offer as faithfully copied from sketches made upon the spot, they will furnish their own apology by shewing at once that they are the work of one who is uninstructed and almost entirely unpractised in that art.

The small Fishing. Town of Clovelly is situated in a narrow and precipitous ravine on the north coast of Devon, about 22 miles to the westward of Ilfracombe, and has attracted some notice from the singularly picturesque scenery of itself and its more immediate environs, the general character of which much resembles that of Linton, upon the same coast, so frequently described by modern tourists.

Having understood that, in addition to this recommendation, the 
cliffs near the town presented very ample and numerous sections of the stratified rock of the country; Mr. Buckland and myself were induced to visit it in the course of an excursion which we made in the west during last summer.

The best access to the town from the Hartland road is by a private carriage way which has been cut through the grounds of Sir James Hamlyn. This not only commands several advantageous views of the lofty and well wooded ravine along the declivity of which it winds, but offers in many places, where the rock has been cut away for the purpose of levelling the road, striking instances of that remarkable configuration of the strata, which is said to be characteristic of the grauwacke formation. To that class all the rocks of this neighbourhood may probably be referred. The principal varieties are those known throughout Devonshire by the appellation of dunstone and sbillat; the former answers pretty accurately to the description usually given by mineralogists of that species of graûwacke in which the fragments, supposed to be cemented together by the intervention of a paste resembling the matter of clay slate, are too small to be discerned even by the aid of a considerable magnifier. The latter alternates with the former and is evidently the finer grauwacke slate of the same nomenclature. Of these rocks the coast between Clovelly presents the most magnificent and interesting sections which we met with in the course of our tour. Both varieties sometimes alternating in distinct and well defined strata, sometimes appearing to graduate into each other, and the compact species assuming the external configuration of greenstone or scrpentine. The strata inclined in every direction and describing the most capricious and picturesque forms, both curved and angular, open an abundant field of instruction to the geologist, while they present difficulties of which neither the theory 
of original deposition on an unequal surface, or of subsequent dislocation, appear to promise any plausible solution.*

The average height of the cliffs, as far as we could judge by the eye, is 130 or 140 feet ; they are traversed in many places by steep ravines running from north to south, and numerous outlying masses of rock shew themselves above the sea at a small distance from lowwater mark, a character uniformly presented by the stratified rocks along the whole of the Northern coast.

In some parts the compact grauwacke was wanting for a considerable distance, in such cases the forms which the slate had assumed were rather angular than curvilinear. In the sections of those which have been called saddle-shaped strata, we observed usually that the dip was more precipitous on the western side. In neither variety of the rock could we discover any traces of organic remains, nor could we perceive any imbedded fragments that should indicate their having been formed from the debris of an earlier rock. The strata are traversed by numerous veins of opaque white quartz, but no appearances of any other mineral substances occurred.

The Drawings annexed, (Pl. 33 and 34,) indifferently executed as

* Professor Jameson (Syst. of Min. vol. 3.) has ascribed these appearances to crystallization. As we are always accustomed to regard terms of science as retaining (where the contrary is not expressly stated) the precise sense in which they have hitherto been uniformly received, the use of this expression is perhaps not strictly correct. The external appearance of these rocks is certainly not that of a mass of crystallized matter; and that the phenomenon itself is not invariably connected with the process of crystallizition is evident from the consideration that those rocks which are the most highly crystalline in their texture are the most free from these singular configurations. That these appearances, howerer, may have been effected by a process of Nature, somewhat allalogous to crystallization, and depending possibly upon the same remoter causes, is perhaps the most satisfactory hypothesis that has hitherto been offered on the subject, and such $I$ apprehend to be the opinion of the school of Werner, though somewhat obscured by the adoption of a term implying identity of operation, in a case where the utmost which can be fairly assumed to exist, appears to be a striking analogy.

VOL. II. $\quad 3 \mathrm{R}$ 
they are, will perhaps convey a clearer notion of the singular configuration of these rocks than could be done by words alone. With the exception of one, which gives a faithful resemblance of some remarkable curvatures in the grauwacke of Hartland Point, the whole of the subjects are selected from those which occurred within the first four miles of our walk from Clovelly westward.

Although these singular contortions are not entirely confined to the dunstone and shillat of Devonshire, they yet occur much more constantly in that rock than in the metalliferous schist of Cornwall. In travelling westward we appeared to lose them gradually. At Bosscastle where the rock evidently approaches nearer to the character of killas, (as it is termed by the miner) they still appear pretty frequently at St. Agnes they are much rarer and less capricious.

It is possible that more accurate and minute researches may carry the subdivision of the stratified rocks of this country much further than the present state of our knowledge appears to authorize; but I cannot think that, even with the limited information which we already possess on this subject, it would be assuming too much to establish a line of separation between the rock, which under the provincial names, already mentioned, of dunstone and shillat covers so large a portion of the North of Devon, and that metalliferous slate which lying immediately upon the granite of Dartmoor and Cornwall forms the most considerable portion of the mining tract in both counties. *

The former of these, besides the peculiarities already noticed, is

* I would wish to be understood as speaking cxclusively of the metalliferous slate. That which alternates with limestone at Vesyan, at Padstow, (where it is accompanied by greenstone) and some other spots in Cornwall, will probably be regarded as belonging to a distinct formation. 
destitute: of metallic- veins.. It alternates with transition limestone, and where it does so, occasionally contains organic remains. It alternates:also, in one instance at least, with large beds of a species of: culm. Its veins contain few : or no. extraneous substances besides. common quatzz and; though less frequently, calcareous spar. .

The latter (the Killas of Cornwall) has generally the: silky character ascribed to clay slate. $\dagger$ It is traversed almost throughout its whole extent by frequent veins, or rather dykes, of a porphyritic rock, which forms one variety of the Elvan of the Cornish miners, and which does not occur either in the dunstone or shillat. It has been found to contain at St. Agnes, the topaz, and in various places the tourmalin and the garnet: the veins are frequently occupied by chlorite, by mica, and by crystallized felspar. A considerable part of the tin of Cornwall is obtained from the killas, and the grey ore' of cobalt has repeatedly been found in it. All these minerals have usually been considered as characteristic of the earlier rocks, and none of them are, I believe, stated by the writers of our most esteemed mineralogical systems to occur in that to which they assign the name of grauwacke. $f$

It is not without the greatest diffidence in my own knowledge of the subject and powers of observation that I venture to dissent, even on a mere point of nomenclature, from the opinion of my able and experienced friend Dr. Berger. I cannot however but conceive that

* In the ncighbourhood of Bideford, a little to the west of Ilfracombe, the rock is said to be much traversed by this mineral.

+ May it not be added that its siliceous varieties are of a texture much finer and more compact than that of Dunstone?

$\ddagger$ The following substances also which appear (although less positively) to be restricted to primitive formations by the school of Werner, occur in the killas; wolfram, native silver, horn silver, schiefer spar, actinolite. I believe that the chiastolite has also been found in it. 
Mr. Conybeare on the Strata near Clovelly.

the marked difference between the two great varieties, which appear to include by far the larger part of the stratified rocks occurring in the west of England, is such, as to render it by no means desirable that they should both be designated by the common name of grauwacke; ${ }^{*}$ a name perhaps the more liable to misapplication as it is somewhat indefinite.

* If the reasons which I have ventured to suggest for the propriety of considering the dunstone and shillat as of a formation distinct from that of the killas be not entirely void of foundation, it is perhaps the more desirable that the attention of geologists should be called to the examination of the subject, as it is understood that a large and respectable body of mineralogists are disposed to apply the name of killas to those stratified rocks in the northern part of Great Britain, which have hitherto been considered by the most accurate observers as indisputably belonging to the grauwacke formation. Is it not possible that the frequent, for $I$ apprehend we are scarcely yet entitled to say the total absence of gneiss and mica slate in the mountain groups of Cornwall may have.contributed ta give rise to this opinion? This character however they appear to possess in common with the Hartz, in which Professor Jameson states the clay slate to rest immetiately upon the granite. 


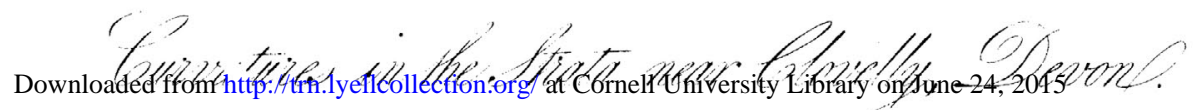
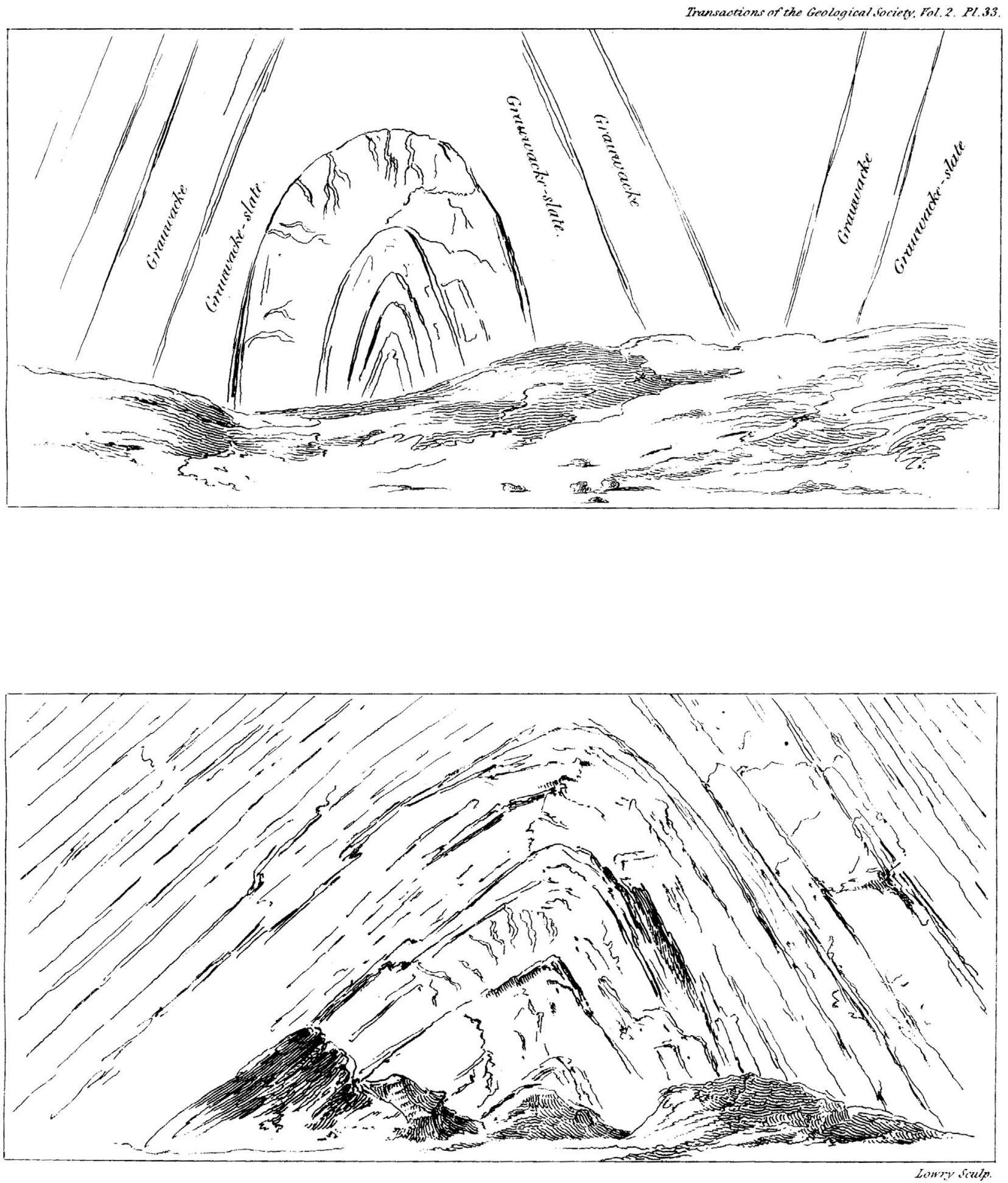


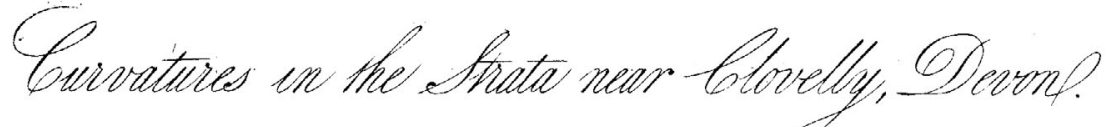

Downloaded from http://trn.lyellcollection.org/ at Cornell University Library on June 24, 2015
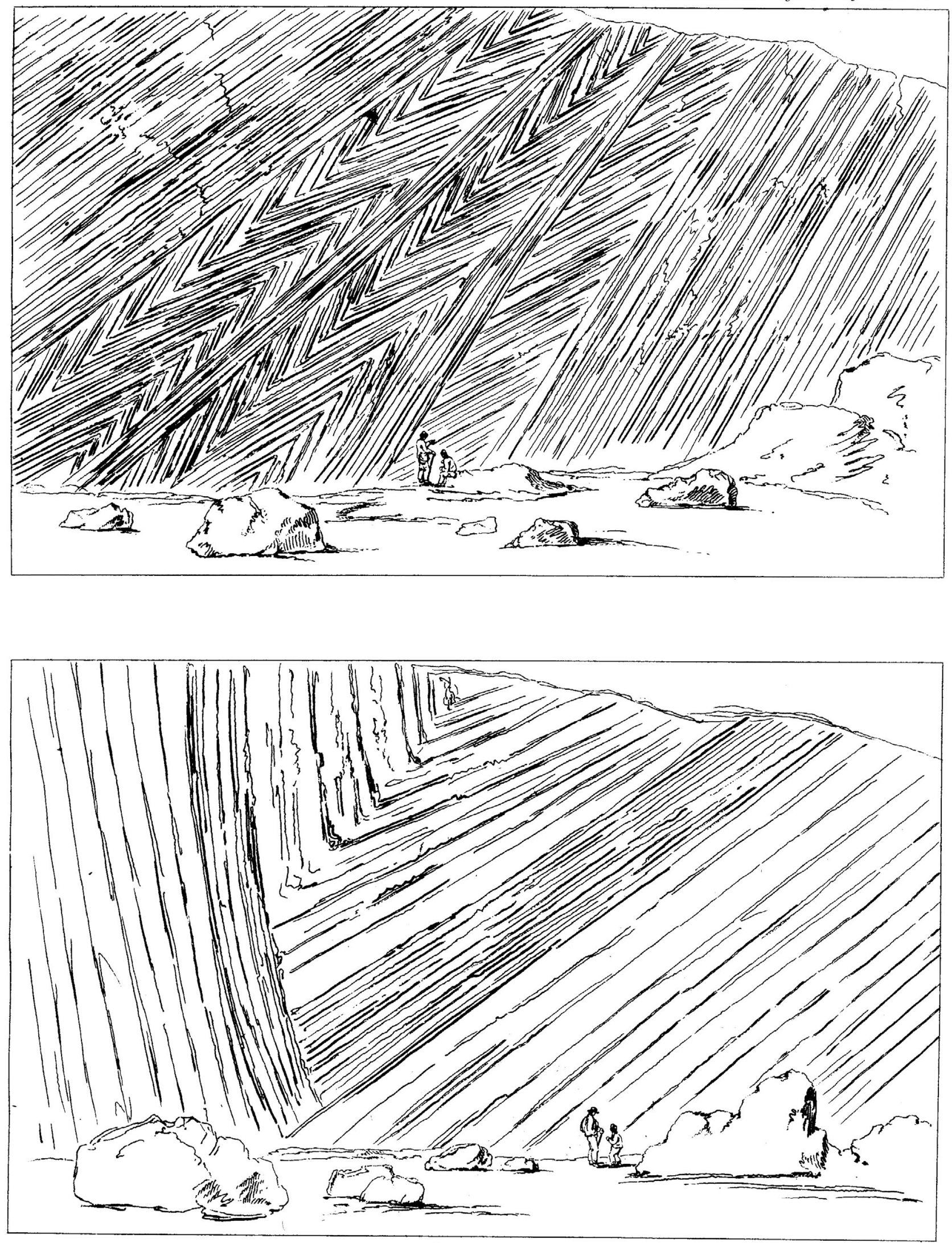


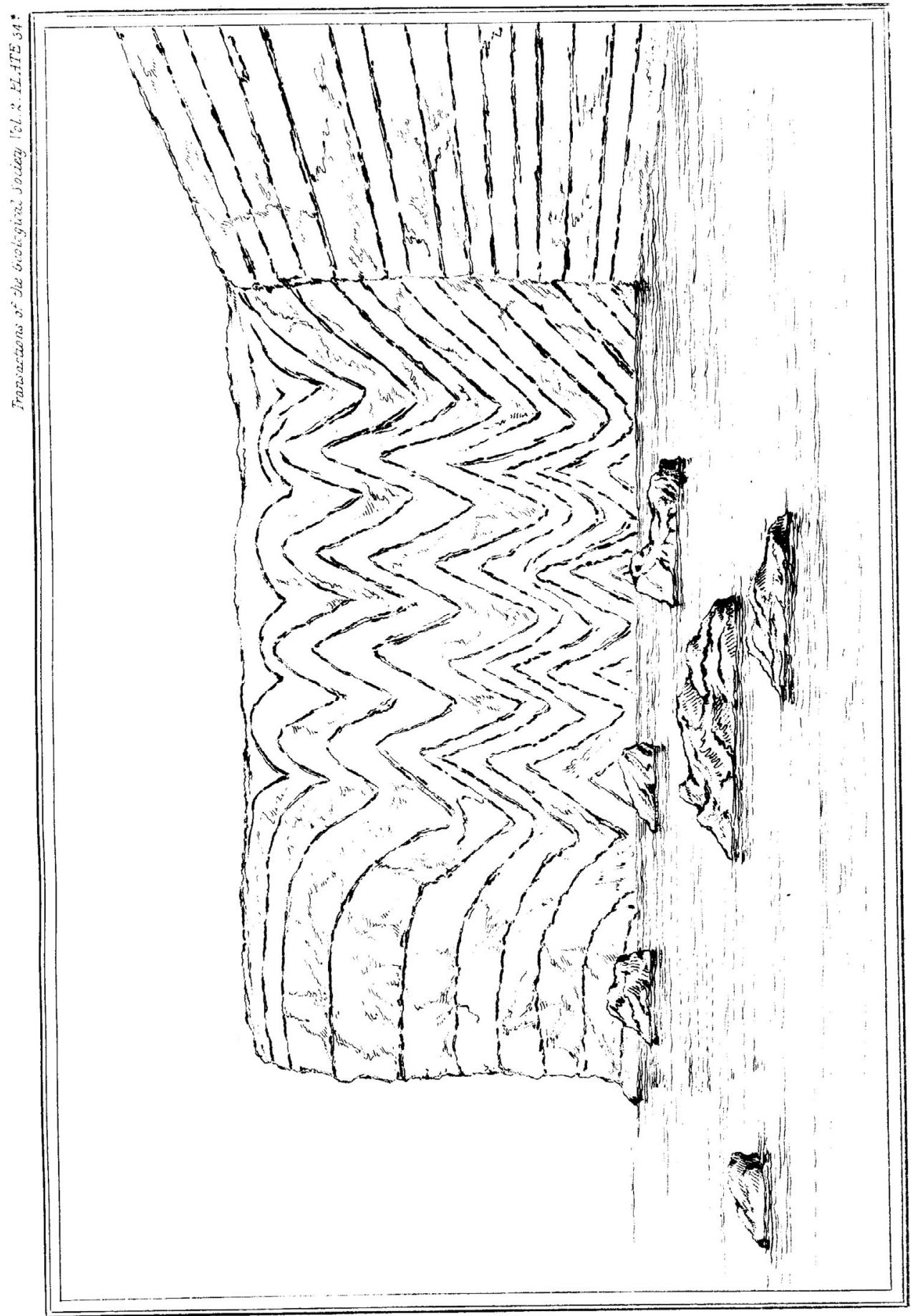

